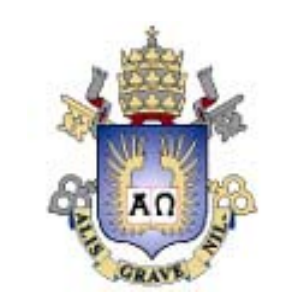

Mariana de Lemos Alves

\title{
Carro Flex Fuel: Uma Avaliação por Opções Reais
}

Dissertação de Mestrado

Dissertação apresentada como requisito parcial para obtenção do título de Mestre pelo Programa de PósGraduação em Administração da PUC-Rio.

Orientador: Prof. Luiz Eduardo Teixeira Brandão

Rio de Janeiro, 12 de março de 2007 


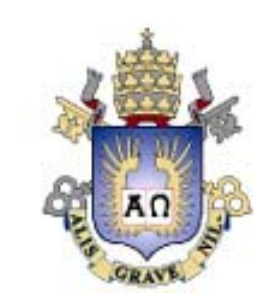

Mariana de Lemos Alves

\title{
Carro Flex Fuel: Uma Avaliação por \\ Opções Reais
}

\begin{abstract}
Dissertação apresentada como requisito parcial para obtenção do título de Mestre pelo Programa de PósGraduação em Administração da PUC-Rio.
\end{abstract}

\author{
Prof. Luiz Eduardo Teixeira Brandão \\ Orientador \\ Departamento de Administração - PUC-Rio \\ Prof. Marco Antonio Guimarães Dias \\ Departamento de Engenharia Industrial- PUC-Rio
}

Prof. Fernando Nascimento de Oliveira

Departamento de Administração - FGV-Rio

Prof. João Pontes Nogueira Vice-Decano de Pós-Graduação do CCS

Rio de Janeiro, 12 de março de 2007 
Todos os direitos reservados. É proibida a reprodução total ou parcial do trabalho sem autorização da universidade, do autor e do orientador.

\section{Mariana Alves}

Graduou-se em Ciências Econômicas pela UFRJ em 2003 e concluiu o mestrado em Administração de Empresas pela PUC RIO em 2007. Atuou nas áreas de planejamento estratégico e Avaliação Econômica de Projetos de Marketing em empresas multinacionais de grande porte. Seus interesses de pesquisa estão relacionados à avaliação de projetos de investimento, avaliação de desempenho corporativo e planejamento estratégico.

Ficha Catalográfica

Alves, Mariana de Lemos
Carro flex fuel: uma avaliação por opções reais I
Mariana de Lemos Alves ; orientador: Luís Eduardo
Teixeira Brandão. - 2007.

94 f. : il. ; $30 \mathrm{~cm}$

Dissertação (Mestrado em Administração)-Pontifícia Universidade Católica do Rio de Janeiro, Rio de Janeiro, 2007.

Inclui bibliografia

1. Administração - Teses. 2. Finanças. 3. Opções reais. 4. Carro flex fuel. 5. Modelo de simulação com fluxos de caixa dinâmicos. I. Brandão, Luis Eduardo Texeira. II. Pontifícia Universidade Católica do Rio de Janeiro. Departamento de Administração. III. Título. 


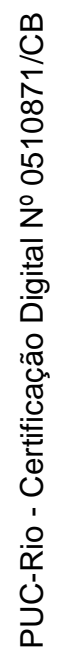

Aos meus pais. 


\section{Agradecimentos}

Agradeço ao professor Luiz Brandão pela orientação e todo apoio neste trabalho.

Ao Bruno Garrofé por todo apoio, troca de idéias, opinião, ajuda em diversas ocasiões.

A minha família por toda compreensão e apoio em todos os momentos e decisões da minha vida. 


\section{Resumo}

Alves, Mariana De Lemos.; Brandão, Luiz Eduardo Teixeira. Carro Flex Fuel: Uma Avaliação por Opções Reais. Rio de Janeiro, 2007. 94p. Dissertação de Mestrado - Departamento de Administração, Pontifícia Universidade Católica do Rio de Janeiro.

A tecnologia flex fuel foi desenvolvida pelo centro de pesquisas da Bosch do Brasil e lançado comercialmente no país em 2003. O conceito desse automóvel originou-se da possibilidade do carro utilizar como combustível álcool, gasolina ou qualquer proporção de mistura entre os dois em um mesmo tanque de combustível. Essa flexibilidade na escolha do combustível do carro flex fuel e a existência de incerteza com relação ao preço do álcool e da gasolina, agregam valor ao automóvel, pois o consumidor pode escolher o combustível mais barato toda vez que abastece o veículo. Este trabalho busca valorar essa vantagem do carro flex fuel em relação ao automóvel movido apenas à gasolina através da avaliação por Opções Reais, utilizando o Método de Simulação com Fluxos de Caixa Dinâmicos, e comparar as vantagens da Simulação de Monte Carlo em relação ao modelo de Árvore de Decisão Quadrinomial. Os resultados indicam que a opção inerente ao carro flex fuel é relevante para a decisão de adquirir um veiculo flex fuel e pode representar de $5 \%$ a $10 \%$ do seu valor.

\section{Palavras-chave}

Finanças; Opções Reais; Carro Flex Fuel; Modelo por Simulação com Fluxos de Caixa Dinâmicos 
Abstract

Alves, Mariana De Lemos.; Brandão, Luiz Eduardo Teixeira. Flex Fuel Car: A Real Option Valuation . Rio de Janeiro, 2007. 94p. Dissertação de Mestrado - Departamento de Administração, Pontifícia Universidade Católica do Rio de Janeiro.

The flex fuel car technology was developed by the Bosch Research Center in Brazil, and the firs model was launched in the market in 2003. The concept of flex fuel automobile derived from the possibility of using ethanol, gas or any proportion of this mixture in a fuel tank. The fuel flexibility and its price volatility add value to the vehicle because the consumer has the option to choose the cheapest fuel each time he needs it. We perform the valuation of the flex fuel automobile using Real Options Approach to Dynamic Cash Flow Simulation. The results show that the value of the flex fuel option is significant and can represent from $5 \%$ to $10 \%$ of the price of the automobile. We also compare this method to the quadrinomial decision tree model and show that while both provide similar results, the simulation method is similar and less computationally intensive.

\section{Keywords}

Finance; Real Options; Flex Fuel Car; Dynamic Cash flow Simulation Model 


\section{Sumário}

1 Introdução 12

1.1. O Problema 15

1.2. Objetivo 16

1.3. Relevância do Estudo 17

1.4. Histórico do Carro Flex Fuel 17

1.5. Estrutura da Dissertação 20

2 Referencial Teórico 22

2.1. A Teoria das Opções Reais 23

2.1.1. Histórico 23

2.1.2. Opções Financeiras 24

2.1.3. Volatilidade 25

2.1.4. O Modelo Black-Scholes-Merton 28

2.1.5. Movimento Geométrico Browniano 30

2.1.6. Opções Reais 31

2.2. Método 1: Árvore Quadrinomial 34

2.2.1. Modelo Binomial Simples 35

2.2.2. Árvore Binomial Múltipla 42

2.2.3. Modelo Quadrinomial 44

2.3. Método 2: Simulação 47

3 Comparação entre os Métodos 49

3.1. Modelo da Árvore Quadrinomial 50

3.2. Modelo de Simulação com Fluxos de Caixa Dinâmicos 53

3.3. Comparação dos Modelos 54

4 Aplicação ao Carro Flex Fuel 58

4.1. Introdução 58

4.2. Opção Flex Fuel $\quad 59$ 
4.3. Premissas 60

4.4. Modelo Financeiro 61

4.5. Preço dos Combustíveis 62

4.6. Série de Inflação 63

4.7. Preços dos Combustíveis Deflacionados 66

4.8. Volatilidade dos Preços dos Combustíveis 67

4.9. Solução 69

5 Conclusões e Recomendações $\quad 75$

5.1. Conclusões 75

5.2. Limitações Metodológicas 76

5.3. Sugestões para Trabalhos Futuros $\quad 77$

$\begin{array}{ll}6 \text { Referências Bibliográficas } & 79\end{array}$ 


\section{Lista de figuras}

Figura I - Produção Acumulada por tipo de Combustível..................................... 13

Figura II - Comportamento do Preço de uma Ação ............................................... 35

Figura III - Comportamento do Preço de uma Opção .............................................. 36

Figura IV - Avaliação Neutra ao Risco............................................................... 38

Figura V - Exemplo I Modelo Binomial.............................................................40

Figura VI - Exemplo II Modelo Binomial ..........................................................40

Figura VII - Modelo Binomial com Três Períodos................................................. 42

Figura VIII - Preço da Ação no Modelo Binomial com Três Períodos ................. 43

Figura IX - Árvore Quadrinomial com dois períodos........................................... 46

Figura X - Custo do Combustível com o Carro Flex Fuel ..................................... 52

Figura XI - Valor da Opção Flex Fuel Variando a Volatilidade do Álcool ......... 73

Figura XII - Valor da Opção Flex Fuel Variando a Volatilidade da Gasolina..... 73

Figura XIII - Valor da Opção Flex Fuel Variando o Consumo de Combustível.. 74 


\section{Lista de tabelas}

Tabela I - Comparativo entre Opções Reais e Financeiras 33

Tabela II - Probabilidade Neutra ao Risco 51

Tabela III - VP do Custo com Combustível usando Árvore Quadrinomial 55

Tabela IV - VP do Custo com Combustível usando Simulação 56

Tabela V - VP do Custo com Combustível: Árvore Quadrinomial x Simulação 56

Tabela VI - Produção por Combustível - 2000/2005 58

Tabela VII - Participação da Produção por Combustível - 2000/2005 58

Tabela VIII - Vendas Internas no Atacado por Combustível - 2000/2005 59

Tabela IX - \%Vendas Internas no Atacado por Combustível - 2000/2005 59

Tabela X - Relação Preço Álcool x Gasolina 61

Tabela XI - Parâmetros adotados na avaliação $\quad 62$

Tabela XII - Preços dos Combustíveis: Álcool e Gasolina 63

Tabela XIII - Volatilidade do Preço do Álcool 68

Tabela XIV - Volatilidade do Preço da Gasolina 69

Tabela XV - Gasto com Combustível no Fluxo Dinâmico Gasolina 72

Tabela XVI - Gasto com Combustível no Fluxo Dinâmico Álcool e Gasolina 72

Tabela XVII - Indicadores de Inflação Nacionais $\quad 89$

Tabela XVIII - IGP-M: Número Índice Mensal e Acumulado 90

Tabela XIX - Valor do Álcool a Preços de Outubro de 2006

Tabela XX - Valor da Gasolina a Preços de Outubro de 2006

Tabela XXI - Variação Percentual do Álcool a Preços de Outubro de 200693

Tabela XXII - Variação Percentual da Gasolina a Preços de Outubro de 200694 